\title{
Elderly patients with COPD require more health care than elderly heart failure patients do in a hospital-based home care setting
}

This article was published in the following Dove Press journal: International Journal of Chronic Obstructive Pulmonary Disease

\author{
Hans Lennart Persson' \\ Johan Lyth ${ }^{2}$ \\ Ann-Britt Wiréhn ${ }^{2}$ \\ Leili Lind ${ }^{3,4}$
}

'Respiratory Medicine, Department of Medical and Health Sciences (IMH), Linköping University, Linköping, Sweden;

${ }^{2}$ Research and Development Unit in Region Östergötland and Department of Medical and Health Sciences, Linköping University, Linköping, Sweden;

${ }^{3}$ Department of Biomedical Engineering/ Health Informatics, Linköping University, Linköping, Sweden; ${ }^{4}$ Rise Research Institutes of Sweden Ab/Division Ict Sics East, Linköping University, Linköping, Sweden
Correspondence: Hans Lennart Persson Department of Medical and Health Sciences (IMH), Linköping University, SE58I 85, Linköping, Sweden

$\mathrm{Tel}+46 \quad 10 \quad 1033621$

Email lennart.persson@liu.se
Background: Elderly patients with advanced stages of COPD or chronic heart failure (CHF) often require hospitalization due to exacerbations. We hypothesized that telemonitoring supported by hospital-based home care (HBHC) would detect exacerbations early, thus, reducing the number of hospitalization. We also speculated that patients with advanced COPD or CHF would present differences regarding exacerbation frequency and the need of HBHC.

Methods: The Health Diary system, based on digital pen technology, was employed. Patients aged $\geq 65$ years with $\geq 2$ hospitalizations the previous year were included. Exacerbations were categorized and treated as either COPD or CHF exacerbation by an experienced physician. All HBHC contacts (home visits or telephone consultations) were registered.

Results: Ninety-four patients with advanced diseases were enrolled (36 COPD and 58 CHF subjects) of which 53 subjects (19 COPD and 34 CHF subjects) completed the 1-year study period. Death was the major reason for not finalizing the study. Compared to the 1-year prior inclusion, the intervention significantly reduced hospitalization. Although COPD subjects were younger with less comorbidity, exacerbations and HBHC contacts were significantly greater in this group.

Conclusions: COPD subjects exhibit exacerbations more frequently, mainly due to disease characteristics, thus, demanding much more HBHC.

Keywords: home care services, hospital-based, telemedicine, digital pen, exacerbation, hospitalization

\section{Introduction}

The population of elderly is rapidly growing. In Sweden 2017, approximately 2 million individuals were $\geq 65$ years, compared to approximately 1.5 million in the year $2000{ }^{1}$ Expected life age for men and women in Sweden 2017 was 80.7 and 84.1 years, respectively, which is a substantial increase compared to the corresponding figures for the year 2000, 77.4 and 82 years, respectively. ${ }^{1}$ Along with old age, serious diseases become more frequent. The prevalence of chronic heart failure (CHF) among Swedish age $\geq 80$ years during recent years is estimated to $10 \%{ }^{2}$ Correspondingly, the Swedish prevalence of COPD is $8 \%$ already at 50 years and increase by age. ${ }^{3}$

Advanced stages of both diseases, that is, New York Heart Association (NYHA) Functional Classification, class 3-4 for CHF subjects and GOLD, stage III-IV/class C and $\mathrm{D}$ for COPD subjects, cause severe disability. ${ }^{4,5}$ Dyspnea is a characteristic feature of both diseases, which initially is exertional, and as the diseases progress, appears at 
rest as well. ${ }^{4,5}$ Edema is associated with $\mathrm{CHF}$, while patients with COPD demonstrate chronic cough, which often is associated with increased mucus production. ${ }^{4,5}$ Both diseases may demonstrate episodes of worsening of these symptoms, so-called exacerbations. ${ }^{4,5}$ At such occasions, CHF patients are often relieved by a combination of fluid restriction and diuretics. ${ }^{4}$ In contrast, moderate and severe exacerbation of COPD, which is often associated with an inflammatory response in the respiratory tract to an infection, demands antibiotics, alone or in combination with steroids. ${ }^{5}$ Unless treatments are initiated at an early stage of the deterioration, elderly, fragile patients with advanced stages of CHF or COPD commonly require visits to the emergency room and ensuing hospitalization due to an exacerbation.

During the last 15 years, there has been a growing number of telehealth studies and reviews including patients with $\mathrm{CHF}$ and/or COPD. Some of these have shown a reduced morbidity and mortality as well as positive effects on exacerbation and hospitalizations. ${ }^{6-15}$ However, to become successful, the introduction of a new home telemonitoring system in healthcare needs to be accepted by professional caregivers as well as patients. ${ }^{16}$ In Sweden 2018, approximately 500,000 individuals never use the internet. ${ }^{17}$ The majority of these individuals are $\geq 75$ years. ${ }^{17}$ Possible barriers to using internet and telecommunication technologies are aging that can affect the functioning of sensory and motor organs, ${ }^{18,19}$ but the most common reasons given are "no interest" and "complicated technology." ${ }^{17,20}$ Considering this lack of familiarity to internet use, we thought it is feasible to employ the telemonitoring system, the Health Diary, which is based on digital pen technology. In a previous study, we used this technology to monitor the well-being in a group of elderly multi-diseased subjects, in which CHF was the dominating cause for frequent contacts with the health care and re-admissions to hospital. $^{21,22}$ In this small pilot study $(n=14)$, exacerbations of CHF were detected early, treatment was initiated at home by a specialized hospital-based home care (HBHC) unit, and hospitalization was thereby avoided. Indeed, in this setting, none of the included subjects were hospitalized during the surveillance period of 13 months. ${ }^{21,22}$ This very favorable outcome urged us to perform a larger study to further develop the system, and for better understanding of the impact of chronic cardio-pulmonary morbidity on elderly, we decided to include subjects with CHF and COPD, thus, enabling a comparison of the diseases.

Studies comparing CHF subjects and COPD subjects regarding the frequency of exacerbations and consequent health care contacts in populations are surprisingly scarce.
In a Scottish study from 2010, which analyzed contact rates in primary health care, contact rates for $\mathrm{CHF}$ and COPD were observed. ${ }^{23}$ In those with both conditions, contact rates were greater than disease-specific contact rates in subjects with either condition alone. ${ }^{23}$ Considering the above-mentioned disease characteristics of CHF and COPD, we hypothesized that subjects with CHF or COPD - in an HBHC setting of fragile, elderly patients with advanced stages of diseases - would exhibit differences regarding exacerbation frequency and subsequent need of health care, ie, hospitalization and HBHC contacts. The rationale was to compare the healthcare utilization of elderly, very sick patients with frequent hospitalizations, the latter dominated by either COPD or CHF, but not excluding patients with both diagnosis. Thus, providing a real-life perspective as CHF and COPD commonly co-exist. Indeed, patients with the most advanced form of COPD commonly present with right-heart failure due to emphysema and ensuing hypoxemia. Primary outcome was exacerbation frequency and home health care contacts appearing during the intervention, thus, comparing COPD and CHF subjects. Secondary outcome was the number of hospitalizations during a 1-year intervention, compared to the number of hospitalizations of the same subjects the 1-year prior inclusion. The causes behind hospitalization, urgent or planned, were of interest. The subjects' experiences regarding their ability to handle the technology and method, their participation in their own care, their knowledge of the illness and their feeling of security were also assessed.

\section{Materials and methods}

\section{Setting and usual care}

The study setting was the Hospital-Based Homecare (HBHC) unit, Linköping University Hospital, which provides specialized homecare to patients diagnosed with advanced CHF and COPD. Usual care, before the present study was started, could consist of a treatment period from a few days to several weeks, depending on the patient's condition. Treatment for CHF patients usually includes intravenous injections or infusion of diuretics and changes in medications. Treatment for COPD patients usually includes inhalations, steroids and antibiotics. Most patients are usually visited frequently in their homes for the follow-up of their health status. Usually, the patient is discharged to primary care, when he/she is considered stable with respect to $\mathrm{CHF} / \mathrm{COPD}$. 


\section{Study design}

Forms and equipment

The researchers, professional caregivers and the company Phoniro Systems AB, Halmstad, Sweden (https://www.pho niro.com) formed a group with the purpose of considering all requirements on system functionality together with usability aspects, and to further develop and tailor the system. Besides keeping the system's functionality from the pilot study, ${ }^{22}$ new functionality was implemented, allowing a larger group of patients to send in their reports daily without any loss of incoming data. The digital pen technology (Anoto Group, Lund, Sweden; www.anoto.com), described in more detail elsewhere, ${ }^{24}$ consists of an ink pen with a digital infrared camera that records everything the pen writes or draws on any paper imprinted with the Anoto Pattern - a non-repeating dot pattern nearly invisible to the naked eye, but used by the pen to establish its exact location. The pen strokes are recorded and transferred via mobile internet to a server (www.anoto.com) where they are interpreted. ${ }^{24}$

Three Health Diary forms were designed (Figure 1); the yellow form to cover respiratory symptoms and medications, the green form to cover shortness of breath, weight changes, and medication and the blue form to cover different measurements (Figure 1). COPD subjects and CHF subjects reported daily using the yellow form and the green form, respectively. If decided by the responsible physician, the subjects (both COPD and CHF subjects) could also use the blue form to report on measurements.
In collaboration with the researchers and the $\mathrm{HBHC}$ clinic, Phoniro Systems AB designed, developed, tested and implemented the care provider part of the Health Diary system; a web-based application for receiving, storing, managing, and displaying incoming patient reports. Historical outcome measure data can be shown in graphs and as numbers in the user interface. Physicians and nurses were instructed on how to use the web-based application. At inclusion, all study subjects were informed that they also could contact the clinic by phone if necessary.

\section{Study cohort}

Inclusion criteria for participation were: ability to provide written informed consent, $\geq 65$ years, COPD and/or CHF, $\geq 2$ hospital admissions due to CHF or COPD during the last 12 months. Exclusion criteria comprised dementia, other cognitive impairment or psychotic illness, not able to understand Swedish (because of the questionnaires in Swedish used), severe hearing loss, past surgery in the last 6 months or planned within 6 months ahead, or other lifethreatening illness. Ninety-eight patients were approached for this study and asked for participation. Three patients with CHF and one patient with COPD declined to participate giving 94 patients, who agreed to participate.

Subjects were recruited during a 3-years period and the last included subject was followed another year, leading to a 4-year study, from November 2013 to December 2017. Planned inclusion period was 12 months for each
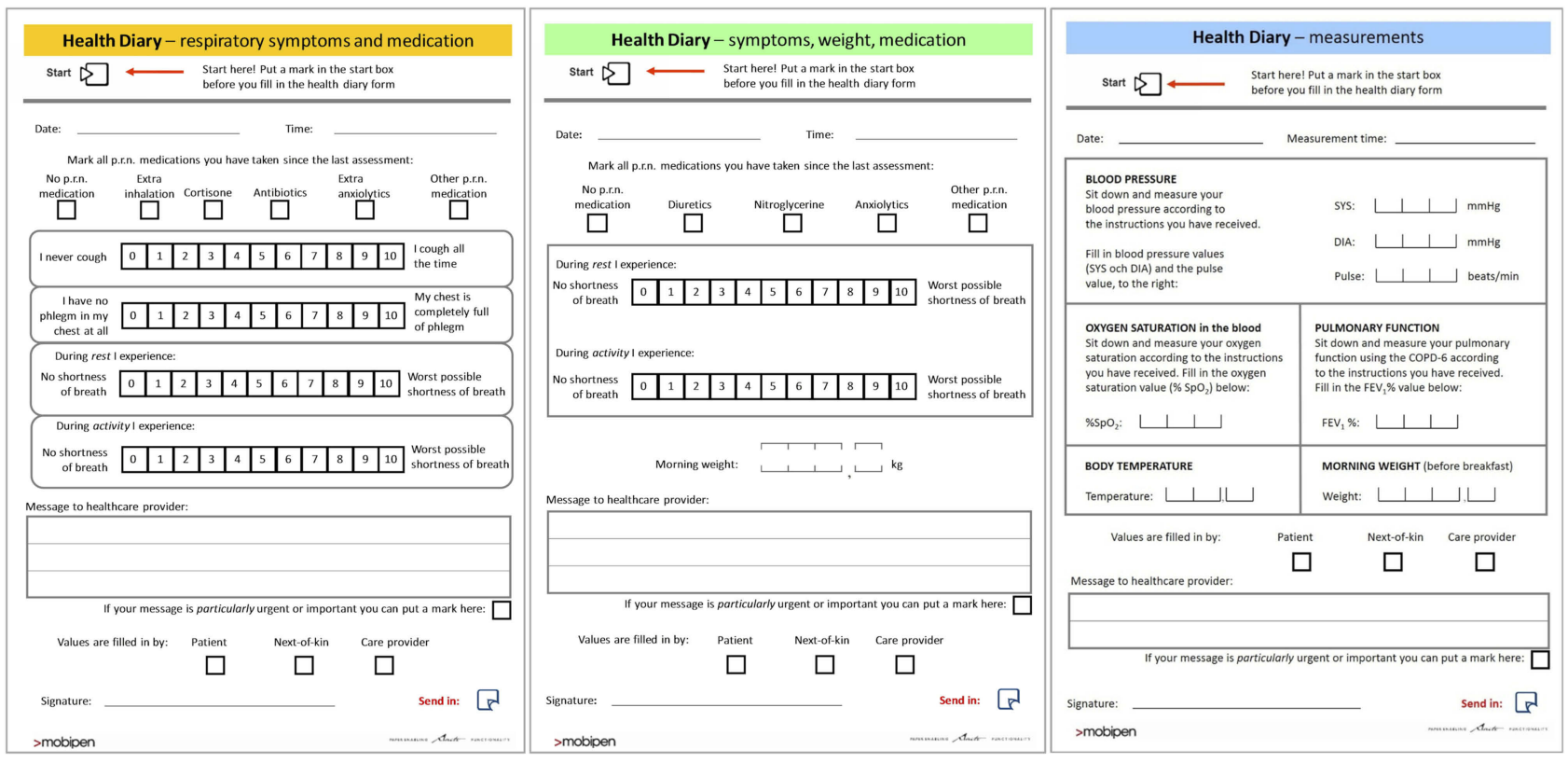

Figure I The Health Diary forms. 
participating subject. At inclusion, the study subject was designated to either the COPD group or the CHF group, depending on the disease that dominated the clinical picture, that is, the disease that was the main reason behind hospital admissions during the 12 months prior to inclusion. During their study participation, none of the subjects were discharged from the HBHC unit to primary care. However, for other health conditions, not related to $\mathrm{CHF} /$ COPD, the subjects were referred to primary care or other care providers during the study period.

\section{Ethics}

The study was approved by the Regional Ethical Review Board in Linköping, Sweden (no. 213/309-31) and was registered at ISRCTN (ISRCTN34252610). The study was conducted in accordance with the Declaration of Helsinki, the guidelines of the International Conference on Harmonization of Good Clinical Practice (ICH-GCP), and the applicable Swedish laws. It was required that study subjects gave informed written consent before participation.

\section{Intervention}

The intervention consisted of subjects' daily reporting by use of a digital pen and a Health Diary form. All subjects were to report daily on symptoms and intake of medications taken as needed using the green (CHF subjects) and yellow (COPD subjects) forms. Further, all CHF subjects were to measure their weight (using the subject's own scale or a Marquant, No. 820-199, P.R.C.) and report this on the green form. Additionally, if decided by the responsible physician, some subjects were asked to report on measurements, such as blood pressure (using an Omron i-C10 blood pressure monitor; OMRON Healthcare Europe, Hoofddorp, the Netherlands), pulse and oxygen saturation (SAT) (using a pulse-oximeter; NONIN 2500 PalmSat, Plymouth, MN, USA), and body temperature, during a shorter or longer period, using the blue form.

The Health Diary forms also allowed free text messages from the subjects, thus, providing additional information on the subjects' health status. Alarms were generated if reported values were outside of predetermined individual limits. These limits were adjusted and individualized by the responsible physician. Alarms were also generated if a subject failed to send in a report or if the care providers forgot to check and sign the patient reports in time. ${ }^{21,22}$ The alarm type was shown with an icon in the Health Diary system, and different alarms had different icons. Additionally, more serious alarms, such as low oxygen saturation or an increased breathlessness, were also shown as Short Message Service (cellular phone text messaging) text messages in a mobile phone used by one of the nurses. Included study subjects were thoroughly instructed by a study nurse to correctly handle the equipment. The health professionals at the specialized HBHC unit, responsible for both subject surveillance and the medical actions taken, checked the Health Diary system daily and were thereby immediately informed about the subjects' health status.

Subjects received home visits when needed, decided by a responsible physician or nurse. If a subject's reports indicated a deteriorated health or showed a beginning exacerbation, the nurse or physician first contacted the subject by phone and decided thereafter if a home visit was necessary.

\section{Outcome parameters}

Primary outcome was exacerbation frequency and home health care contacts appearing during the intervention, thus, comparing COPD and CHF subjects. Secondary outcome was the number of hospitalizations during a 1-year intervention, compared to the number of hospitalizations of the same subjects the 1-year prior inclusion. Since not all subjects completed the 1-year study period, study months were compared with the same number of months immediately prior to inclusion. The causes for hospitalization, urgent or planned, were assessed for the study period. Data originates from patient records. The study also sought to assess the subjects' experience regarding their ability to handle the technology and method, their participation in their own care, their knowledge of the illness, and their feeling of security.

At inclusion, subjects with COPD were also asked to fill in the mMRC questionnaire (scoring dyspnea in daily life on a scale from 0 to 4 ) and COPD Assessment Test (8 questions scoring COPD symptoms from 0 to 5 , thus, providing a total score 0-40) for GOLD classification. Demographic data were collected at baseline (gender, age, smoking status, pack-year, etc.), along with vital parameters, such as blood pressure, heart rate, body temperature, SAT, and body weight. Further, height and calculated body mass index (BMI) were recorded, and blood was sampled for analysis. Comorbidities were documented at baseline and scored accordingly using Charlson Comorbidity index (CCI). Exacerbations and hospitalizations were registered continuously. At 1, 6, and 12 months of inclusion, study subjects also 
filled in questionnaires about their ability to handle the technology and method, their participation in their own care, their knowledge of the illness and their feeling of security.

\section{Statistical analysis}

The results are reported as the mean $\pm 1 \mathrm{SD}$ (range) for continuous variables. Two-sided $t$-tests were used for continuous normally distributed variables (paired was used for comparison in the same group and unpaired was used for comparison between two groups) and Pearson's chisquared test for categorical variables. IBM SPSS Statistics, vs 6, was used (IBM SPSS, Chicago, IL, USA).

\section{Results}

\section{Differences between COPD- and CHF subjects}

A total of 94 patients, $58 \mathrm{CHF}$ and $36 \mathrm{COPD}$ subjects were included in the study. Characteristics of the study subjects are summarized in Table 1.

There were $50 \%$ and $61 \%$ women in the CHF and the COPD groups, respectively (Table 1). All subjects included were frequently hospitalized during a 12-month period prior inclusion, but no significant difference was observed between the two groups (Table 1). At inclusion, all subjects, although being very fragile demonstrated stable vital parameters (heart rate, blood pressure, body temperature, morning weight; data not presented). Mean age was significantly lower, and tobacco consumption was significantly greater among COPD subjects (Table 1). Moreover, COPD subjects had less comorbidity and were thinner than $\mathrm{CHF}$ subjects, reflected by a significantly lower CCI and BMI (Table 1). SAT was significantly lower among COPD subjects (Table 1). Indeed, 7 (19\%) COPD subjects were on long-term oxygen therapy. All but one subject in the COPD group had advanced COPD. In the CHF group, 17 subjects (29\%) had COPD as well. However, compared to the COPD group, these subjects exhibited significantly greater lung volumes, here presented as $\mathrm{FEV}_{1}$ (\% predicted), and GOLD stages and grades were less advanced. Importantly, COPD was not the cause for health contacts and hospitalization for these subjects in the CHF group. Conversely, in the COPD group, 22 subjects also suffered from CHF. All 22 subjects demonstrated severe deconditioning, reflected by NYHA 3-4. Nevertheless, despite both advanced stages of COPD and NYHA class, COPD - not CHF - dominated the clinical picture of these subjects. In addition, exacerbations of COPD were the cause for health care contacts before and during the study period.

White blood cell count was significantly higher among COPD subjects, while CHF subjects demonstrated significantly higher levels of creatinine. The level of B-type natriuretic protein (proBNP), a marker of CHF, was generally elevated among CHF subjects, while the level of the stable metabolite of vitamin $\mathrm{D}, 25(\mathrm{OH}) \mathrm{D}$, which mainly reflects UV exposure due to outdoor activities, was sufficient $(\geq 50$ nmol/L) among 24 COPD-subjects (67\%; Table 1).

\section{Death was the major reason for not completing the study}

The proportions completing the study period of 12 months were approximately the same in both groups; $55 \%$ in the CHF group and 53\% in the COPD group (Table 2). The major reason for not finalizing the study period was death; $28 \%$ in the CHF group and $36 \%$ in the COPD group (Table 2). Other reasons to stop study participation were physical or cognitive deterioration or change of residency, mostly by moving to a nursing home (Table 2). Assessable study months per included study subjects did not differ significantly, when the two groups were compared (Table 2).

\section{COPD-subjects exacerbate more often, demanding more health care}

Only 2 subjects of 36 subjects $(6 \%)$ in the COPD group had no exacerbations, while 23 subjects of 58 subjects (40\%) in the CHF group had no exacerbations. Thus, COPD-subjects demonstrated significantly more diseasespecific exacerbations (Table 3). This resulted in significantly more home visits by the HBHC physician (Table 3). Overall, the COPD-subjects demanded significantly more care, reflected by more home visits and phone calls (Table 3).

The variables monitored differed in appearance when exacerbations of CHF and COPD were compared. This is illustrated in Figure 2, which shows the appearance of a representative CHF exacerbation (A) and a representative COPD exacerbation (B). Data are from the Health Diary system. For the CHF subject (Figure 2A) symptoms are preceded by a weight gain, appearing slowly over time (not shown in the Figure), which culminates by breathlessness, first occurring upon activity and then also at rest. These symptoms disappear as soon as the patient is stabilized by medications, at this occasion initiated at day 7 , when a nurse visited the patient at 
Table I Characteristics of the study sample CHF- versus COPD-subjects. Results are presented as mean \pm I SD (range) for continuous variables and percentage for categorical variables. $P$-values are from Chi-square test and Student's $t$-test $(P$-value $\geq 0.05)$

\begin{tabular}{|c|c|c|c|}
\hline & CHF $(n=58)$ & COPD $(n=36)$ & $P$-value \\
\hline Age & $83 \pm 7(65-100)$ & $75 \pm 6(65-86)$ & $<0.001$ \\
\hline Women, n (\%) & $29(50)$ & $22(6 I)$ & n.s. \\
\hline \multicolumn{4}{|l|}{12 months prior inclusion } \\
\hline Times hospitalized, all causes & $3.1 \pm 1.5(2-10)$ & $3.4 \pm 1.8(2-9)$ & n.s. \\
\hline Current smokers, n (\%) & $2(3)$ & $10(29)$ & $<0.05$ \\
\hline Ex-smokers, n (\%) & $31(54)$ & $25(7 \mathrm{I})$ & n.s. \\
\hline Never smokers, n (\%) & $25(43)$ & $0(0)$ & $<0.05$ \\
\hline Pack-year & $8 \pm 13(0-59)$ & $38 \pm 19(1-100)$ & $<0.001$ \\
\hline BMI & $27 \pm 5(16-43)$ & $24 \pm 6(|2-4|)$ & $<0.01$ \\
\hline SAT (\%) & $95 \pm 3(82-99)$ & $90 \pm 6(70-98)$ & $<0.001$ \\
\hline Subjects on LTOT, n (\%) & $0(0)$ & $7(19)$ & \\
\hline $\mathrm{CCl}$, mean $(\mathrm{SD})$ & $4.9(2.3)$ & $3.4(2.0)$ & $<0.001$ \\
\hline \multicolumn{4}{|l|}{$\mathrm{CCl}, \mathrm{n}(\%)$} \\
\hline $0-1$ & $4(7)$ & $5(14)$ & n.s. \\
\hline 2 & $4(7)$ & $9(25)$ & $<0.05$ \\
\hline 3 & $6(10)$ & $12(33)$ & $<0.05$ \\
\hline$\geq 4$ & $44(76)$ & $10(28)$ & $<0.05$ \\
\hline Subjects with COPD, n (\%) & $17(29)$ & $36(100)$ & \\
\hline FEV ( $\%$ predicted), COPD subjects only & $58 \pm 18(23-96)$ & $39 \pm 15(13-79)$ & $<0.001$ \\
\hline \multicolumn{4}{|l|}{ GOLD stage, n (\%) } \\
\hline I-II & $13(76)$ & $3(8)$ & $<0.05$ \\
\hline III & $3(18)$ & $7(20)$ & n.s. \\
\hline IV & I (6) & $26(72)$ & $<0.05$ \\
\hline \multicolumn{4}{|l|}{ GOLD grade, $\mathrm{n}(\%)$} \\
\hline$A-B$ & $6(35)$ & I (3) & $<0.05$ \\
\hline $\mathrm{C}$ & $0(0)$ & $0(0.0)$ & n.s. \\
\hline D & II (65) & $35(97)$ & $<0.05$ \\
\hline Subjects with CHF, n (\%) & $58(100)$ & $22(61)$ & \\
\hline \multicolumn{4}{|l|}{ NYHA-class, n (\%) } \\
\hline 3 & $46(79)$ & $20(9 l)$ & $<0.05$ \\
\hline 4 & $12(21)$ & $2(9)$ & $<0.05$ \\
\hline WBC (ref: $3.5-8.8 \times 10 * 9 / L)$ & $7.8 \pm 1.9(4.2-12.4)$ & $10.9 \pm 4.8(5.6-32.7)$ & $<0.001$ \\
\hline hsCRP (ref: <10 mg/L) & $14.7 \pm 16.3(0.7-93)$ & $29.1 \pm 58.9(0.3-343)$ & n.s. \\
\hline Hemoglobin (ref: 134-170 g/L) & $127 \pm 17(95-167)$ & $130 \pm 17(102-172)$ & n.s. \\
\hline Creatinine (ref: $45-90 \mu \mathrm{mol} / \mathrm{L}$ ) & $134 \pm 63(64-488)$ & $83 \pm 30(43-164)$ & $<0.001$ \\
\hline ProBNP (ref: <1800 ng/L) & $6036 \pm 6232(410-35,000)$ & - & \\
\hline $25(\mathrm{OH}) \mathrm{D}$ (ref: $\geq 50 \mathrm{nmol} / \mathrm{L})$ & - & $60 \pm 28(|I-| 4 \mid)$ & \\
\hline
\end{tabular}

Abbreviations: BMI, body mass index; CCl, Charlson Comorbidity Index; CHF, chronic heart failure; hs-CRP, high sensitivity $\mathrm{C}$ reactive protein; LTOT, long-term oxygen therapy; NYHA, New York Heart Association Functional Class; 25(OH)D, the stable metabolite of vitamin D; proBNP, B-type natriuretic protein; SAT, blood oxygen saturation; WBC, white blood cell count; n.s., not significant.

home and initiated an increased dose of diuretics. Note that symptom scales returned to the baseline already within a couple of days. In contrast, breathlessness was a common sign of a COPD exacerbation, appearing first at activity and then also at rest (Figure 2B). If the medical actions were not immediately taken, ie, increased use of inhalations, and if needed, antibiotics or/and oral steroids, breathlessness was followed by a decline of SAT. As the subject was improved on medication, SAT and symptom scores slowly reached their baselines. Indeed, as in this case, breathlessness on activity score often remained on a higher level, despite that SAT was normalized. In the present case, medical actions were taken on 
Table 2 Study performance. Results are presented as mean \pm 1 $\mathrm{SD}$ (range) for continuous variables and percentage for categorical variables. $P$-values are from Chi-square test and Student's $t$ test $(P$-value $\geq 0.05)$

\begin{tabular}{|c|c|c|c|}
\hline & $\begin{array}{l}\text { CHF } \\
(n=58)\end{array}$ & $\begin{array}{l}\text { COPD } \\
(n=36)\end{array}$ & $\begin{array}{l}P \text { - } \\
\text { value }\end{array}$ \\
\hline Completed 12 study months, $\mathrm{n}$ (\%) & $32(55)$ & $19(53)$ & n.s. \\
\hline $\begin{array}{l}\text { Did not complete } 12 \text { study } \\
\text { months, } \mathrm{n}(\%)\end{array}$ & $26(45)$ & $17(47)$ & n.s. \\
\hline \multicolumn{4}{|l|}{ Reasons behind early exclusion } \\
\hline $\begin{array}{l}\text { - Death, n (\%) } \\
\text { - Deterioration, n (\%) } \\
\text { - Change of residency, n (\%) }\end{array}$ & $\begin{array}{l}16(28) \\
6(10) \\
4(7)\end{array}$ & $\begin{array}{l}13(36) \\
2(6) \\
2(6)\end{array}$ & $\begin{array}{l}\text { n.s. } \\
\text { n.s. } \\
\text { n.s. }\end{array}$ \\
\hline \multicolumn{4}{|l|}{ Study months } \\
\hline $\begin{array}{l}\text { - Total } \\
\text { - Per study subject }\end{array}$ & $\begin{array}{l}484 \\
8.4 \pm 4.5 \\
(0-12)\end{array}$ & $\begin{array}{l}280 \\
7.8 \pm 4.8 \\
(0-12)\end{array}$ & n.s. \\
\hline
\end{tabular}

Abbreviations: $\mathrm{CHF}$, chronic heart failure; n.s., not significant.

day 7. Both patients (Figure 2A and B) were successfully treated at home during their exacerbations. As the responsible staff got familiar with the telemonitoring system and the disease behavior of each individual, actions were taken at an earlier stage in most cases and changes of variables from baselines became less pronounced.

\section{Intervention reduced hospitalization frequency}

Secondary outcome of the present study was to assess whether a combination of telemonitoring and HBHC would reduce the frequency of hospitalizations compared to the year prior to study inclusion. Data originates from patient records. Results are summarized in
Table 4. Hospitalization rate prior inclusion, compared to during the study period, did not differ significantly, when the groups were compared. Since the number of months prospectively studied during the study were fewer $(8.4 \pm 4.5$ and $7.8 \pm 4.8$ for CHF and COPD subjects, respectively) than the number of months prior to study intervention (12 months per every subject) retrospectively evaluated, hospitalization rates prior inclusion for both groups were adjusted accordingly, see "Materials and methods" section for details (Table 4). Compared to adjusted hospitalization rates prior inclusion, the intervention significantly reduced hospitalization rates for both groups (Table 4).

During intervention, hospitalizations were categorized as either disease-specific - urgent or planned - or due to other causes. Data originates from patient records. Results are summarized in Table 5. Although the total need of hospitalization during the study period did not differ significantly between the two groups (Table 5), the need of urgent disease-specific hospitalization, ie, due to exacerbation of either $\mathrm{CHF}$ or COPD, was significantly less among CHF subjects (Table 5).

\section{Subjects found the telemonitoring system easy to handle}

The subjects' experiences regarding their ability to handle the technology and method, their participation in their own care, their knowledge of the illness and their feeling of security were evaluated at 1, 6 and 12 months of participation using questionnaires. Results are summarized in Table 6.

The collective responses to Q1-Q11 reflected a great satisfaction with the telemonitoring system used, and

Table 3 Primary outcome; exacerbation frequency and home health care contacts. Results are presented as means \pm I SD (range) for continuous variables. $P$-values are from Student's $t$-test $(P$-value $\geq 0.05)$

\begin{tabular}{|c|c|c|c|}
\hline & $\mathrm{CHF}^{\mathrm{a}}(\mathrm{n}=58)$ & $\operatorname{COPD}^{b}(n=36)$ & $P$-value \\
\hline Disease-specific exacerbations per subject & $0.8 \pm 0.9(0-5)$ & $3.2 \pm 2.7(0-10)$ & $<0.001$ \\
\hline \multicolumn{4}{|l|}{ Home care visit per subject } \\
\hline $\begin{array}{l}\text { - By physician } \\
\text { - By nurse } \\
\text { - By physiotherapist } \\
\text { - By dietician } \\
\text { - By curator } \\
\text { Total home care contacts (home visits \& phone calls) }\end{array}$ & $\begin{array}{l}8.0 \pm 4.5(1-18) \\
28.8 \pm 18.8(2-87) \\
2.3 \pm 2.2(0-9) \\
0.2 \pm 0.7(0-4) \\
0.0 \pm 0.1(0-1) \\
67.4 \pm 38.0(5-187)\end{array}$ & $\begin{array}{l}11.2 \pm 7.9(1-32) \\
41.6 \pm 49.4(2-251) \\
2.7 \pm 3.2(0-12) \\
0.5 \pm 0.8(0-3) \\
0.9 \pm 2.1(0-9) \\
94.4 \pm 84.4(3-334)\end{array}$ & $\begin{array}{l}<0.05 \\
\text { n.s. } \\
\text { n.s. } \\
\text { n.s. } \\
\text { n.s. } \\
<0.05\end{array}$ \\
\hline
\end{tabular}

Notes: ${ }^{\mathrm{a} D e m a n d i n g}$ diuretics; ${ }^{\mathrm{b}}$ demanding antibiotics and/or steroids.

Abbreviations: CHF, chronic heart failure; n.s., not significant. 

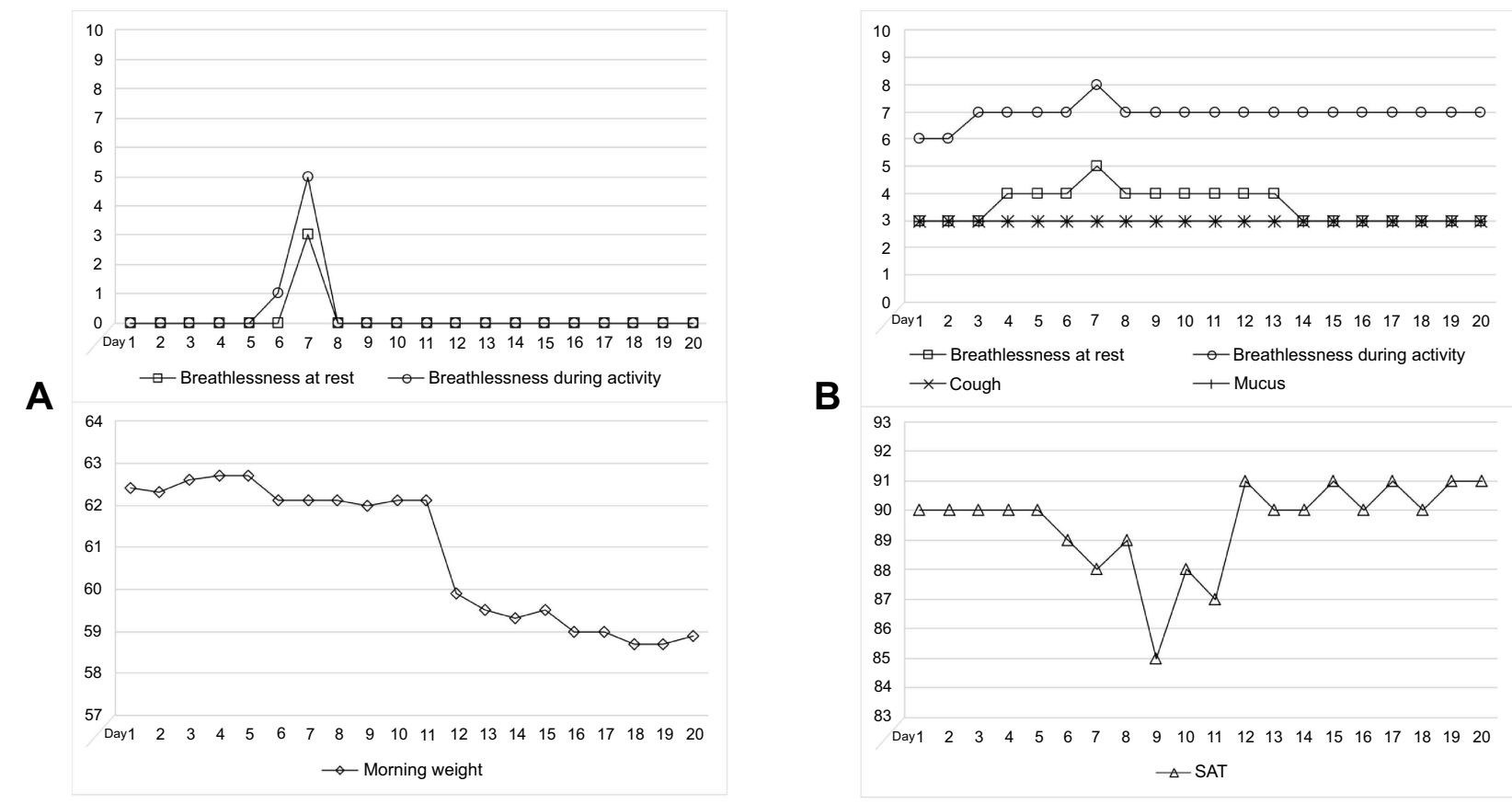

Figure 2 The figures illustrate exacerbations of (A) CHF and (B) COPD. A time span of 20 days is shown. Data are from the Health Diary system.

Table 4 Secondary outcome; times of hospitalization. Results are presented as means \pm I SD (range) for continuous variables and percentage for categorical variables. $P$-values are from Student's $t$-test $(P$-value $\geq 0.05)$

\begin{tabular}{|c|c|c|c|}
\hline & CHF $(n=58)$ & COPD $(n=36)$ & $P$-value \\
\hline Times hospitalized 12 months prior inclusion, all causes, per subject & $3.1 \pm 1.5(2-10)$ & $3.4 \pm 1.8(2-9)$ & n.s. \\
\hline Times hospitalized during study period, all causes, per subject & $0.8 \pm 1.3(0-7)$ & $1.2 \pm 1.5(0-6)$ & n.s. \\
\hline \multicolumn{4}{|l|}{ Assessable months in the study } \\
\hline - Prior inclusion & 696 & 432 & \\
\hline - During the study & 484 & 280 & \\
\hline - \% of planned study months & 70 & 65 & \\
\hline \multicolumn{4}{|l|}{ After adjustment for assessable months } \\
\hline -Times hospitalized prior inclusion, all causes, per subject & $* * * 2.1 \pm 1.1(1.4-7)$ & $* * 2.2 \pm 1.2(1.3-5.8)$ & n.s. \\
\hline
\end{tabular}

$* * *<0.001$ vs "during study period"; $* *<0.01$ vs "during study period".

Abbreviations: CHF, chronic heart failure; COPD, chronic obstructive pulmonary disease; N.s., not significant.

Table 5 Hospitalization during study period specified as disease-specific - urgent or planned - or due to other causes. Results are presented as means \pm I SD (range). $P$-values are from Student's $t$-test $(P$-value $\geq 0.05)$

\begin{tabular}{|l|l|l|l|}
\hline & CHF (n=58) & COPD (n=36) & P-value \\
\hline Disease-specific hospitalization per subject, urgent & $0.1 \pm 0.3(0-1)$ & $0.6 \pm 0.9(0-4)$ & $<0.0$ I \\
Disease-specific hospitalization per subject, planned & $0.0 \pm 0.1(0-1)$ & $0.2 \pm 0.6(0-3)$ & n.s. \\
Hospitalization per subject due to other causes & $0.7 \pm 1.3(0-7)$ & $0.5 \pm 1.0(0-4)$ & n.s. \\
\hline
\end{tabular}

Abbreviations: CHF, chronic heart failure; n.s., not significant. 
Q12-Q15 showed a positive impact on the subjects' own experience of their health status. The responses were also maintained over time.

\section{Discussion}

To the best of our knowledge, this is the first study that shows that elderly patients with frequent exacerbations of advanced COPD demand much more health care than elderly patients with frequent exacerbations of CHF do. During the study period, COPD subjects exacerbated significantly more often than the CHF subjects did and exhibited significantly more hospitalizations and home care due to the urgent need to treat COPD exacerbations. Overall, the intervention supplied - a combination of telemonitoring and $\mathrm{HBHC}$ - significantly reduced hospitalization frequency for both COPD and CHF subjects compared to the status prior inclusion. Considering that COPD subjects were significantly younger than CHF subjects were and had significantly less comorbidity, the differences described are probably best explained by different disease characteristics and different exacerbation pattern. It might be that most exacerbations of CHF are earlier and easier detected, and further, that deterioration is more easily prevented, and treatment is more efficient compared to exacerbations of COPD. The method of reporting with a digital pen and a Health Diary form were well accepted and easy to handle by patients, and the health care personnel found the webbased telemonitoring system easy to use.

The results of the present study are best understood in the light of two previous studies, which also assessed differences of COPD and CHF subjects in terms of exacerbations and health care contacts. ${ }^{23,25}$ As already mentioned, the Scottish study by Hawkins et al concluded that contact rates for $\mathrm{CHF}$ and COPD were greater in those with both CHF and COPD than disease-specific contact rates in subjects with either condition alone. ${ }^{23} \mathrm{~A}$ significant difference between the two diseases alone was not demonstrated. ${ }^{23}$ This study analyzed data from a primary health care register and a great number of patients were included. ${ }^{23}$ The severity of CHF and COPD was, however, not specified. ${ }^{23} \mathrm{~A}$ recently published Italian study by Beghe et al analyzed 3-year hospitalization and mortality in elderly smokers/ex-smokers with COPD or $\mathrm{CHF}^{25}$ This study included 144 COPD and 96 CHF subjects with mild to moderate disease. ${ }^{25}$ Previous hospitalization 12 months prior inclusion was $23.6 \%$ and $22.9 \%$ for COPD and CHF subjects, respectively. ${ }^{25}$ The risk of hospitalization and mortality during the study period did not differ. $^{25}$ Three-year mortality was $14 \%$ and $19 \%$ for COPD and CHF subjects, respectively. ${ }^{25}$ Compared to the study by Beghe et al, ${ }^{25}$ clearly, the patients included in our study were much more fragile, presenting with endstage CHF or COPD, defined by advanced disease stages, repeated hospitalization prior to inclusion and very high 1year mortality; $36 \%$ and $28 \%$ for COPD and CHF subjects, respectively.

CHF and COPD are both diseases causing severe disability in advanced stages. Along with old age, these patients become very fragile. Even a minor exacerbation may lead to a deterioration of the disease, which is sufficient to make hospitalization necessary. Thus, end-stage diseases of COPD and CHF among elderly result in frequent hospitalizations during the end of their lives. ${ }^{26,27}$ Early intervention, using telemonitoring systems for detection of signs of deterioration, is supposed to be of value. ${ }^{13-15}$ However, the results of different telehealth programs for CHF patients differ a great deal. Such programs may ${ }^{6,7}$ or may not ${ }^{4,28,29}$ reduce morbidity and mortality. Despite the inconsistency regarding the outcome, the collective impression of randomized control studies (RCT) performed is that there is a beneficial effect on CHF-related hospitalizations and mortality. ${ }^{13,14}$ Likewise, positive effects by telemonitoring on the frequency of exacerbations and hospitalizations among COPD patients have been demonstrated, ${ }^{10-12}$ while other studies have shown no differences on exacerbation or hospitalization frequency between intervention and control groups. ${ }^{30-32}$

The ways COPD patients may be supervised by remote monitoring were recently summarized by Tomasic et al. ${ }^{33}$ Such patients may be supervised continuously during normal daily activities for the early detection of exacerbations using different sensors to monitor SAT, blood pressure, heart rate, breathing frequency, motions, etc. ${ }^{33}$ Since a COPD exacerbation is defined by the patient's own experience of increased cough, chest tightness and dyspnea, we decided to base the remote monitoring on a questionnaire covering these symptoms. ${ }^{34-36}$ As a complement, vital parameters were monitored in some patients and daily morning body weight was registered for all CHF subjects. COPD subjects were offered the COPD-6-device to monitor airway obstruction, but, since this device was rarely used, sufficient data were not generated. We evaluated the subjects' experience of the telemonitoring system, and it was very well tolerated and accepted. The web-based application used by the staff, when checking patients' reports, was developed in accordance with requirements from physicians and nurses, with the purpose of being easy to learn and use. Considering the 


\begin{tabular}{|c|c|c|c|c|c|c|c|c|c|c|c|c|c|c|c|c|}
\hline 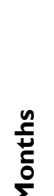 & 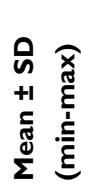 & $\begin{array}{l}\widehat{T} \\
\stackrel{1}{=} \\
0 \\
\vdots \\
+1 \\
+ \\
+ \\
\dot{+}\end{array}$ & $\begin{array}{l}\widehat{1} \\
\stackrel{1}{=} \\
0 \\
0 \\
+1 \\
\infty \\
+ \\
\dot{+}\end{array}$ & 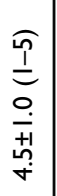 & 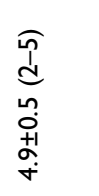 & 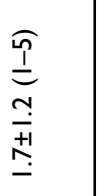 & 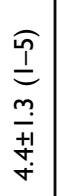 & 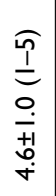 & 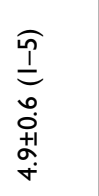 & $\begin{array}{l}\widehat{a} \\
\stackrel{1}{0} \\
0 \\
0 \\
+1 \\
0 \\
\dot{+} \\
\dot{1}\end{array}$ & 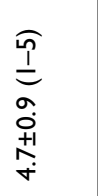 & $\begin{array}{l}\widehat{\Lambda} \\
\stackrel{1}{+} \\
\infty \\
0 \\
+1 \\
+1 \\
+\end{array}$ & 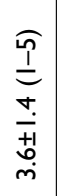 & 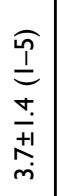 & 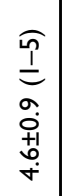 & $\begin{array}{l}\frac{1}{1} \\
\stackrel{1}{=} \\
0 \\
\frac{1}{+1} \\
\stackrel{+1}{+} \\
\dot{\sigma}\end{array}$ \\
\hline$\simeq$ & $\mathbf{z}$ & $g$ & $\hat{f}$ & $\stackrel{\infty}{+}$ & $\stackrel{\infty}{\stackrel{\infty}{+}}$ & in & $\stackrel{\infty}{q}$ & q & $\stackrel{\infty}{q}$ & $\stackrel{q}{q}$ & $g$ & g & $\stackrel{g}{f}$ & $q$ & $\stackrel{q}{q}$ & q \\
\hline $\begin{array}{l}\frac{n}{\tilde{L}} \\
\underline{0}\end{array}$ & 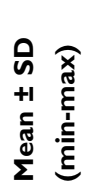 & 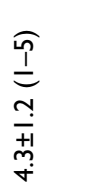 & 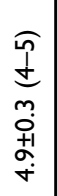 & 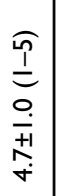 & 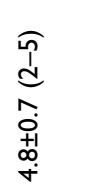 & 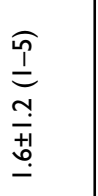 & $\begin{array}{l}\frac{1}{p} \\
\stackrel{p}{=} \\
m \\
\stackrel{m}{+1} \\
m \\
\dot{v}\end{array}$ & 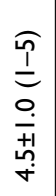 & 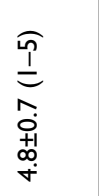 & 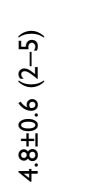 & $\begin{array}{l}\widehat{\Gamma} \\
\stackrel{1}{=} \\
\infty \\
0 \\
+1 \\
+1 \\
+\end{array}$ & 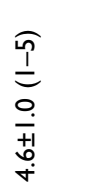 & $\begin{array}{l}\frac{1}{1} \\
\stackrel{1}{=} \\
m \\
\frac{1}{+1} \\
o \\
m\end{array}$ & 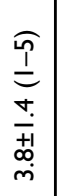 & 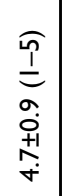 & 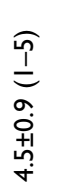 \\
\hline 2 & $z$ & นำ & กิ & น น & กี & น̊ & น゚ & นำ & นึ & 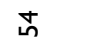 & นn & นn & ڤ̊ & น̊ & ڤ̊ & น̊ \\
\hline 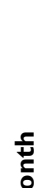 & 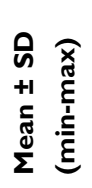 & 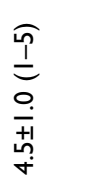 & $\begin{array}{l}0 \\
\hat{1} \\
m \\
m \\
m \\
0 \\
0+1 \\
0 \\
\dot{0}\end{array}$ & $\begin{array}{l}0 \\
1 \\
d \\
a \\
o \\
o \\
+1 \\
0 \\
\dot{+}\end{array}$ & 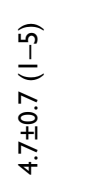 & $\begin{array}{l}\frac{0}{1} \\
\stackrel{1}{=} \\
= \\
+\dot{+1} \\
\stackrel{+1}{\underline{n}}\end{array}$ & 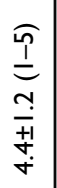 & $\begin{array}{l}\frac{1}{1} \\
\stackrel{1}{=} \\
0 \\
\frac{.}{+1} \\
\stackrel{+1}{+} \\
\stackrel{+}{*}\end{array}$ & 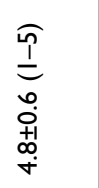 & $\begin{array}{l}\widehat{0} \\
\stackrel{1}{o} \\
a \\
o \\
+1 \\
+1 \\
\dot{\forall}\end{array}$ & 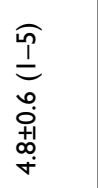 & 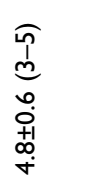 & $\begin{array}{l}\frac{1}{1} \\
\stackrel{1}{n} \\
\frac{n}{+} \\
+1 \\
\dot{+1} \\
m\end{array}$ & 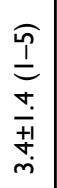 & 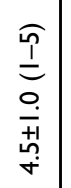 & 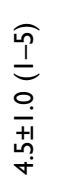 \\
\hline 2 & $\mathbf{z}$ & $\stackrel{m}{\wedge}$ & ก & $\stackrel{\circ}{\wedge}$ & $\stackrel{\star}{N}$ & $\stackrel{\infty}{\wedge}$ & $\stackrel{\circ}{\wedge}$ & $\stackrel{\infty}{\wedge}$ & N & 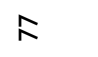 & ז & t & $\stackrel{n}{\wedge}$ & 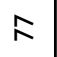 & 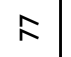 & 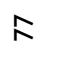 \\
\hline & 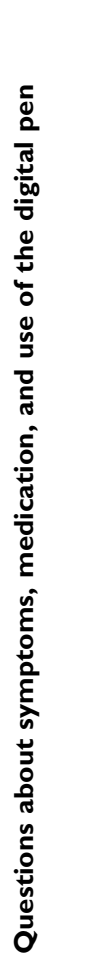 & 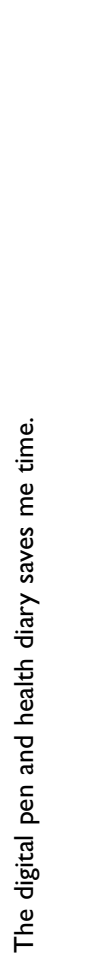 & 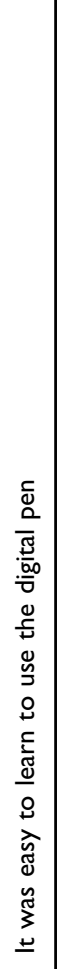 & 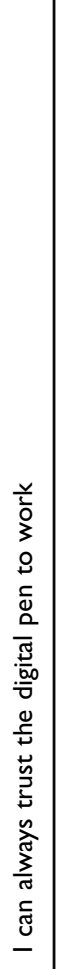 & 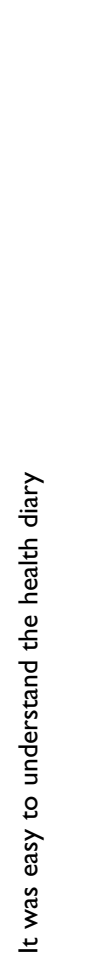 & 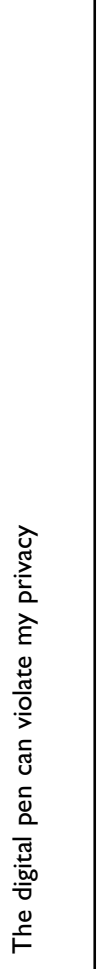 & 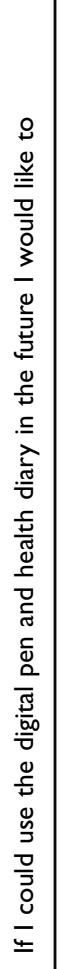 & 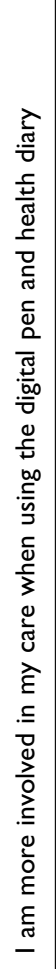 & 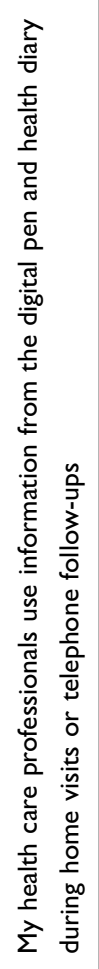 & 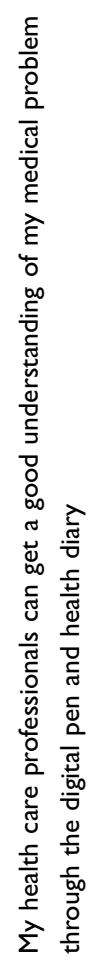 & 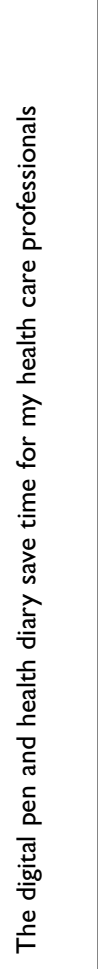 & 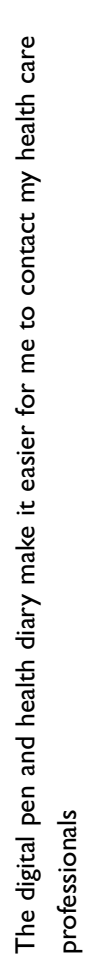 & 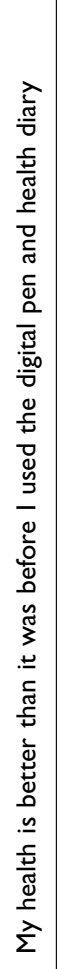 & 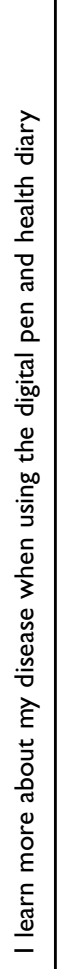 & 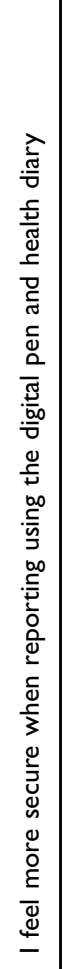 & 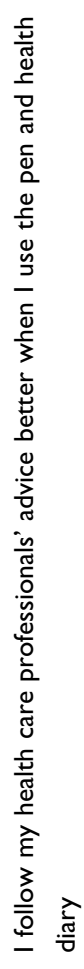 \\
\hline & 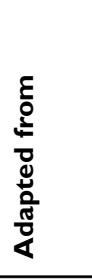 & 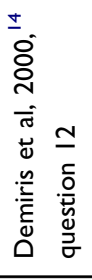 & 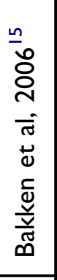 & 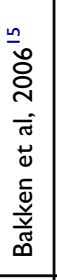 & 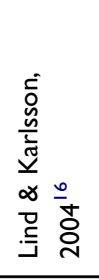 & 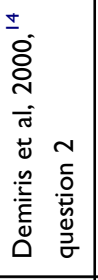 & 1 & 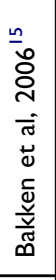 & 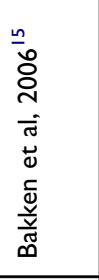 & 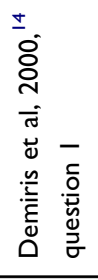 & 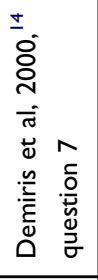 & 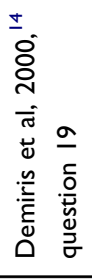 & 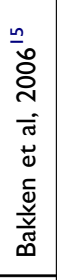 & 1 & 1 & 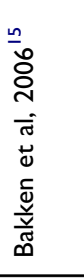 \\
\hline & 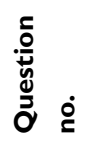 & - & $N$ & $m$ & $\sigma$ & in & 0 & $\wedge$ & $\infty$ & $\sigma$ & $\underline{\underline{O}}$ & $=$ & $\simeq$ & $\underline{m}$ & \pm & $\underline{\underline{n}}$ \\
\hline
\end{tabular}


varying results on outcomes by different modes of telemonitoring, documented in a recent review covering 46 RCTs on COPD patients, ${ }^{15}$ we found our results very satisfactory.

The present study has weaknesses. Firstly, it is not an RCT. For the secondary outcome, which was analysis of hospitalization frequency, historical data were used. However, since disease history of every subject was very thoroughly investigated, using patient records, we believe that this study design may provide data with great safety. Secondly, among COPD subjects, which were those that demonstrated most exacerbations and hospitalizations, a substantial number of subjects presented with NYHA functional class 3-4 (22 subjects, 61\%). COPD patients very often suffer from CHF as well, which mostly engages the right ventricle due to pulmonary hypertension secondary to advanced lung disease and hypoxemia. ${ }^{5}$ Since most of these subjects were not investigated further regarding cardiac dysfunction, using blood analysis of proBNP or echocardiography, we cannot entirely rule out the possibility that some of these subjects also had left- or biventricular failure and that it was the combination of COPD and CHF, rather than COPD per se, that made these COPD subjects more fragile. Speaking against this notion, however, is the fact that every exacerbation and every hospitalization occurring in the COPD group were thoroughly categorized by physicians well acquainted with the characteristics of exacerbations of both diseases and the typical disease pattern of the study subject; indeed, all these events taking place in the COPD group were regarded as due to COPD deterioration (not due to CHF) and were treated successfully as such.

\section{Conclusion}

In the present study, COPD subjects exhibited exacerbations more frequently than CHF subjects did, thus, demanding much more home health care. We consider this difference mainly due to disease characteristics. Moreover, the remote monitoring reduced both diseasespecific and all-causes hospitalization significantly.

\section{Abbreviation list}

BMI, body mass index; CCI, Charlson Comorbidity Index; $\mathrm{CHF}$, chronic heart failure; $\mathrm{FEV}_{1}(\%$ of predicted $)$, forced expiratory volume in $1 \mathrm{~s}$ expressed as \% of predicted; HBHC, specialized hospital-based home careICH-GCP, International Conference on Harmonization of Good Clinical Practice; NYHA, New York Heart Association; proBNP, B-type natriuretic protein; RCT, randomized control study; SAT, blood oxygen saturation.

\section{Acknowledgments}

The authors thank all the patients in this study for their committed participation in this research and all the health professionals at the Unit of Specialized HBHC for dedicated health care. In particular, the authors would like to thank Dr. G. Carlgren, Dr. J. Mudra and R.N. H. Synnergren (study nurse) for collecting most of the data. This work was supported by grants from the county council of Östergötland (Region Östergötland), the European Regional Development Fund through the NovaMedTech venture, and RISE Research Institutes of Sweden AB. This study was performed at the Unit of Specialized HBHC, Linköping University Hospital, Sweden.

\section{Manuscript originality disclaimer statement}

The manuscript is original, is not under consideration by any other journal, and has not previously been published. Parts of early results were presented in poster sessions on the ERS conference 2015, Amsterdam, the Netherlands (Lind L, Carlgren G, Mudra J, Synnergren H, Hilding N, Karlsson D, Wiréhn A-B, Persson HL (2015)). Preliminary results of a telemonitoring study: COPD and heart failure patients exhibit great difference in their need of health care. European Respiratory Journal 2015 46: PA2790; DOI: 10.1183/ 13993003.congress-2015.PA2790 and the ERS conference 2018, Paris, France (Lind L, Lyth J, Karlsson D, Wiréhn AB, Persson HL (2018)). COPD patients require more health care than heart failure patients. European Respiratory Journal 2018 52: PA743; DOI: 10.1183/13993003.congress-2018. PA743.

\section{Author contributions}

H.L.P. and L.L. designed and led the study, collected and analyzed the data, and wrote the manuscript. J.L. and A.B. W. both participated in the manuscript writing, while A.B. W. also participated in the study design. All authors contributed to data analysis, drafting or revising the article, gave final approval of the version to be published, and agree to be accountable for all aspects of the work.

\section{Disclosure}

H.L.P. has received honoraria for advisory boards/lectures from AstraZeneca, Boehringer Ingelheim, Novartis, Takeda Nycomed, Almirall, Intermune and Roche. H.L.P. reports personal fees from AstraZeneca, Boehringer Ingelheim, Novartis, Takeda Nycomed, Almirall, Intermune, Roche, 
outside the submitted work. L.L. reports grants from the county council of Region Östergötland and from The European Regional Development Fund, during the conduct of the study. The authors report no other conflicts of interest in this work.

\section{References}

1. SCB, befolkningsstatistik i sammandrag 1960-2017. Available from: http://www.scb.se/hitta-statistik/statistik-efter-amne/befolkning/befol kningens-sammansattning/befolkningsstatistik/pong/tabell-och-dia gram/helarsstatistik-riket/befolkningsstatistik-i-sammandrag/. Accessed June 25, 2019.

2. Zarrinkoub R, Wettermark B, Wändell P, et al. The epidemiology of heart failure, based on data for 2.1 million inhabitants in Sweden. Eur J Heart Fail. 2013;15:995-1002. doi:10.1093/eurjhf/hft064

3. Backman H, Eriksson B, Rönnmark E, et al. Decreased prevalence of moderate to severe COPD over 15 years in northern Sweden. Respir Med. 2016;114:103-110. doi:10.1016/j.rmed.2016.03.013

4. Ponikowski P, Voors AA, Anker SD, et al. ESC guidelines for the diagnosis and treatment of acute and chronic heart failure: the task force for the diagnosis and treatment of acute and chronic heart failure of the European Society of Cardiology (ESC). Developed with the special contribution of the Heart Failure Association (HFA) of the ESC. Eur J Heart Fail. 2016;2016(18):891-975. doi:10.1002/ejhf.592

5. Global initiative for chronic obstructive lung disease: global strategy for the diagnoses, management and prevention of chronic obstructive pulmonary disease, 2018 report. Available from: https:/goldcopd.org/wpcontent/uploads/2018/02/WMS-GOLD-2018-Feb-Final-to-print-v2.pdf.

6. Chaudhry SI, Phillips CO, Stewart SS, et al. Telemonitoring for patients with chronic heart failure: a systematic review. J Card Fail. 2007;13:56-62. doi:10.1016/j.cardfail.2006.09.001

7. Polisena J, Tran K, Cimon K, et al. Home telemonitoring for congestive heart failure: a systematic review and meta-analysis. $J$ Telemed Telecare. 2010;16:68-76. doi:10.1258/jtt.2009.090406

8. Polisena J, Tran K, Cimon K, et al. Home telehealth for chronic obstructive pulmonary disease: a systematic review and metaanalysis. J Telemed Telecare. 2010;16:120-127. doi:10.1258/ jtt.2009.090812

9. Steventon A, Bardsley M, Billings J, et al. Effect of telehealth on use of secondary care and mortality: findings from the whole system demonstrator cluster randomised trial. BMJ (Clinical Research Ed). 2012;344:e3874-e. doi:10.1136/bmj.e3874

10. Kamei T, Yamamoto Y, Kajii F, et al. Systematic review and meta-analysis of studies involving telehome monitoring-based telenursing for patients with chronic obstructive pulmonary disease. Jpn J Nurs Sci. 2013;10:180-192. doi:10.1111/j.17427924.2012.00228.x

11. De San Miguel K, Smith J, Lewin G. Telehealth remote monitoring for community-dwelling older adults with chronic obstructive pulmonary disease. Telemed J E Health. 2013;19:652-657. doi:10.1089/ tmj.2012.0244

12. Cruz J, Brooks D, Marques A. Home telemonitoring effectiveness in COPD: a systematic review. Int J Clin Pract. 2014;68:369-378. doi:10.1111/ijcp.12345

13. Inglis SC, Clark RA, Dierckx R, et al. Structured telephone support or non-invasive telemonitoring for patients with heart failure. Cochrane Database Syst Rev. 2015;10:CD007228. doi:10.1002/ 14651858.CD007228.pub3

14. Dierckx R, Inglis SC, Clark RA, et al. Telemedicine in heart failure: new insights from the Cochrane meta-analyses. Eur J Heart Fail. 2017;19:304-306. doi:10.1002/ejhf.759
15. Vitacca M, Montini A, Comini L. How will telemedicine change clinical practice in chronic obstructive pulmonary disease? Ther Adv Respir Dis. 2018;12:1753465818754778. doi:10.1177/1753465818754778

16. Demiris G, Shigaki CL, Schopp LH. An evaluation framework for a rural home-based telerehabilitation network. J Med Syst. 2005;29:595-603.

17. Svenskarna och internet 2018. Report from Internetstiftelsen in Sweden (IIS); 2018. Available from: https://www.iis.se/docs/ Svenskarna_och_internet_2018.pdf. Accessed June 25, 2019.

18. Hanson VL. Technology skill and age: what will be the same 20 years from now? Univ Access Inf Soc. 2011;10:443-452. doi:10.1007/s10209-011-0224-1

19. Foster MV, Sethares KA. Facilitators and barriers to the adoption of telehealth in older adults: an integrative review. Comput Inform Nurs. 2014;32:523-533;quiz 534-5. doi:10.1097/CIN.0000000000000105

20. Wildenbos GA, Peute L, Jaspers M. Aging barriers influencing mobile health usability for older adults: a literature based framework (MOLD-US). Int J Med Inform. 2018;114:66-75. doi:10.1016/j. ijmedinf.2018.03.012

21. Lind L, Karlsson D. Telehealth for "the digital illiterate" - elderly heart failure patients' experiences. Stud Health Technol Inform. 2014;205:353-357.

22. Lind L, Carlgren G, Karlsson D. Old - and with severe heart failure: telemonitoring by using digital pen technology in specialized homecare: system description, implementation, and early results. Comput Inform Nurs. 2016;34:360-368. doi:10.1097/CIN.0000000000000252

23. Hawkins NM, Jhund PS, Simpson CR, et al. Primary care burden and treatment of patients with heart failure and chronic obstructive pulmonary disease in Scotland. Eur J Heart Fail. 2010;12:17-24. doi:10.1093/eurjhf/hfp160

24. Lind L, Berglund A, Berglund E, et al. Effortless data capture for ambient e-services with digital pen and paper technology. In: Designing Solutions-Based Ubiquitous and Pervasive Computing: New Issues and Trends. IGI Global; 2010:24-43.

25. Beghé B, Fabbri LM, Garofalo M, et al. Three-year hospitalization and mortality in elderly smokers with chronic obstructive pulmonary disease or chronic heart failure. Respiration. 2018;11:1-11. doi: $10.1159 / 000492286$

26. Guarascio AJ, Ray SM, Finch CK, et al. The clinical and economic burden of chronic obstructive pulmonary disease in the USA. ClinicoEcon Outcomes Res. 2013;5:235-2345. doi:10.2147/CEOR. S34321

27. Shafie AA, Tan YP, Ng CH. Systematic review of economic burden of heart failure. Heart Fail Rev. 2018;23:131-145. doi:10.1007/ s10741-017-9661-0

28. Anker SD, Koehler F, Abraham WT. Telemedicine and remote management of patients with heart failure. Lancet. 2011;378:731-739. doi:10.1016/S0140-6736(11)61229-4

29. Chaudhry SI, Mattera JA, Curtis JP, et al. Telemonitoring in patients with heart failure. $N$ Engl J Med. 2010;16. doi:10.1056/nejmoa1010029

30. Antoniades NC, Rochford PD, Pretto JJ, et al. Pilot study of remote telemonitoring in COPD. Telemedicine e-Health. 2012;18:634-640. doi:10.1089/tmj.2011.0231

31. Pinnock H, Hanley J, McCloughan L, et al. Effectiveness of telemonitoring integrated into existing clinical services on hospital admission for exacerbation of chronic obstructive pulmonary disease: researcher blind, multicentre, randomised controlled trial. BMJ. 2013;347:f6070. doi:10.1136/bmj.f6070

32. Jódar-Sánchez F, Ortega F, Parra C, et al. Implementation of a telehealth programme for patients with severe chronic obstructive pulmonary disease treated with long-term oxygen therapy. $J$ Telemed Telecare. 2013;19:11-17. doi:10.1177/1357633X12473909

33. Tomasic I, Tomasic N, Trobec R, et al. Continuous remote monitoring of COPD patients - justification and explanation of the requirements and a survey of the available technologies. Med Biol Eng Comput. 2018;56:547-569. doi:10.1007/s11517-0181798-z 
34. Demiris G, Speedie S, Finkelstein S. A questionnaire for the assessment of patients' impressions of the risks and benefits of home telecare. $J$ Telemed Telecare. 2000;6:278-284. doi:10.1258/ 1357633001935914

35. Lind L, Karlsson D. A system for symptom assessment in advanced palliative home healthcare using digital pens. Med Inform Internet Med. 2004;29:199-210.
36. Bakken S, Grullon-Figueroa L, Izquierdo R, et al. Development, validation, and use of English and Spanish versions of the telemedicine satisfaction and usefulness questionnaire. J Am Med Inform Assoc. 2006;13:660-667. doi:10.1197/jamia.M2013

\section{Publish your work in this journal}

The International Journal of COPD is an international, peer-reviewed journal of therapeutics and pharmacology focusing on concise rapid reporting of clinical studies and reviews in COPD. Special focus is given to the pathophysiological processes underlying the disease, intervention programs, patient focused education, and self management protocols. This journal is indexed on PubMed Central, MedLine and CAS. The manuscript management system is completely online and includes a very quick and fair peer-review system, which is all easy to use. Visit http://www.dovepress.com/testimonials.php to read real quotes from published authors. 